Article

\title{
The Systemic and Global Dimension of Business Resilience in a Socio-Technical Perspective
}

\author{
Paulo Garrido ${ }^{1,2}$ \\ 1 Algoritmi Research Center, University of Minho, Campus de Azurém, 4804-533 Guimarães, Portugal; \\ pgarrido@dei.uminho.pt; Tel.: +351-253-510-190 \\ 2 LIAAD-INESCTEC, R. Dr. Roberto Frias, 4200-465 Porto, Portugal
}

Academic Editor: Giuseppe Ioppolo

Received: 7 December 2015; Accepted: 18 February 2016; Published: 27 February 2016

\begin{abstract}
This paper proposes to augment the concept of a business resilience improving process by enlarging such a process with a dimension of external action that addresses the vaster frame of systemic resilience of our societies. To this aim, I propose to widen the concept of socio-technical system (STS) to human societies, based on the idea that the development and survival of human societies has necessary social and technical factors. I also propose a concept of resilience in terms of dealing with failures of STS. Two particular cases of very large failure avoidance are considered: nuclear war and civilizational collapse, and I propose that such cases should be present in the referred dimension of external action of any business resilience program. Because the action of public governments and their cooperation is crucial for advancing global systemic resilience, I suggest that businesses should analyze and model the decisions of governments in a wider context of naturally occurring cooperating and conflicting human groups.
\end{abstract}

Keywords: socio-technical systems; resilience; systemic resilience; resilience functions; businesses and public governance; nuclear war; civilization collapse; quality standards for human societies; UN Declaration of Human Rights

\section{Introduction}

In [1], Katrin Muff (dean of the Business School of Lausanne) questions the perspective that looks at "business resilience" as if it could be meaningfully separated from the vaster problem of systemic resilience of human societies in global terms:

"Shouldn't business care about the resilience of the larger system (the planet and our societies) first, rather than focusing on the survival of a sub-system (business)?"

This dimension of the subject should be taken in consideration in a comprehensive theory of business resilience. Businesses (as we understood them actually) are a form of organization in modern civilization. While there are increasing concerns, initiatives and results in business resilience, the fact remains that the very existence of businesses is bound to the civilization (the system) of which they are organizations (subsystems).

Any theory of individual business resilience must assume that civilization will be resilient enough to sustain itself. Civilization resilience is a necessary condition for business resilience. Without civilization, theories of business resilience are futile because there are no businesses. This means that a theory of business resilience must connect to a theory of civilizational resilience in order to have practically meaningful foundations. It is at least prudent to assess the resilience of the "larger system" if one wants a theory of business resilience centered at the "business" or subsystem level that makes sense. 
A deeper reason to include or connect to a theory of civilization resilience in a theory of business resilience is that both cannot be disjoint because businesses are subsystems of the wider system. The policies (or their absence) to make civilization resilient have consequences for the design of business resilience. This becomes evident when one considers the fundamental resilience any business can have: solvency or bottom-line resilience. It is illustrated as a thought experiment [2] as follows.

Imagine that one has the responsibility of top level decision in a business that has just come to the green in terms of bottom-line: sales revenues equal the required payments and savings. If this is the case, the business should have been performing structurally and functionally well in a viable environment. The next concern for management is to keep the business in such a good condition. The question is what could move the business into negative results territory. Posing this question means that decision-makers begin a "bottom-line business resilience process".

There are two factors to consider and address in this process, one internal and the other external. The internal factor is the organizational and behavioral performance of the business as a business. This can be addressed by establishing an adaptive performance measure consistent with being actually in the green and define a sub-process to maintain and increase performance.

The external factor is demand for the products sold by the business. While it may be quite difficult to master the first factor, the (external) propensity of buyers to buy the business products overplays it. The best performing organization will not make business acting in an environment where buyers of its products do not exist.

This means exactly that there must exist people with interest in the business products and able to pay their fair prices. Maintaining comfortable constant demand or experiencing comfortably increasing demand appears as an optimal environmental condition. This external factor can be addressed establishing a second sub-process inside the resilience process to monitor demand and influence it, if possible.

A prosperous, healthy and wealthy environment will generate a maximum of demand compatible with the environment's resources. This is the systemic property of the environment that maximizes the bottom-line resilience of businesses with respect to demand. Therefore, it must be the target for the sub-process that addresses demand when trying to influence it.

As I will argue in the sequel, the systemic property of prosperity is necessary for civilizational resilience. This global systemic resilience property fuses with the local target of each business towards being bottom line resilient.

One must add to prosperity clean energy and peace to get a resilient civilization. War is not good for business, except for those in the business of war. However, even to these, prosperity and peace can be a very interesting proposal in bottom-line terms if seen as enabling businesses of a transformed kind, as I will suggest.

To sum up, as this thought experiment shows, bottom-line business resilience requires two processes, one to address business performance, the other to address demand for the business products. The targets for the last one align with civilizational resilience targets. What is good for civilization is good for business and vice-versa.

The purpose of this paper is to bring clarification on the external and global systemic dimension of business resilience, to chart some obvious needs and to elicit moves that businesses can take to "care about the resilience of the larger system" as part of the process of increasing business resilience.

The cornerstone of the development is two-fold and presented in Section 2. I propose to widen the concept of socio-technical system (STS) to human societies, based on the idea that the development and survival of human societies has necessary social and technical factors. I will consider the global or planetary civilization an STS-the widest system, or the global STS. Subsystems of the global STS will be, among others, states. A state will be an STS with a terrestrial surface area where it has jurisdiction, nominally at least. Given the flexibility of the system's concept one can also take as an STS any meaningful subsystem as a region or an organization. 
I also propose a concept of resilience as the general function of an STS that deals with its own failures. I conclude that we can distinguish three basic functions in systemic resilience: prediction, counter-measures and information gathering. I take in account that these functions are to be implemented inside a system that is complex by nature.

Two or three basic types of human organizations will implement these functions. These types are public and private, the last one being further divided with the usual labels of non-profit and business. Therefore, the actions of organizations, both public and private, will determine which systemic resilience will exist.

Under the presented sketch of a theory of meta-organizing of organizations into a set of state STSs, a government has a key role in the coordination of the organizations operating in its jurisdiction area, conditioning business survival and reproduction through the monetary coordination mechanism, for which I present some key ideas. The role of governments in the coordination, which occurs in their jurisdictions, conditions businesses and their resilience. From the standpoint of businesses, the function of a government is to enact prosperity in its jurisdiction and contribute to global prosperity. Even before caring for global resilience, economic prosperity must be shown to possible in order to guide governments' decisions. I propose that prosperity may be operationally understood as a society satisfying a quality standard.

In Section 3, I look at business resilience from the standpoint of businesses being subsystems of a socio-technical system and I restate the idea-put forth above-that a business process targeting business resilience should have two sub-processes, one addressing internal factors of failure, the other addressing external factors or threats.

Among the multiple external threats that businesses may face I choose to consider with some detail two that have a top-level character: nuclear war and civilization collapse by economic stratification and resource depletion. A nuclear war would collapse civilization at the fastest pace that one could imagine, so it is in this sense the "greatest threat" to consider. A recent study [3] observed that resource depletion and economic stratification are two factors ever present in the collapse of civilizations. The importance of these threats may perhaps be better appreciated by assuming that if they were not there, the global STS would appear, in practical terms, sustainable in a very 50plus20.org long time frame.

The "top-level" character of these threats comes not only because they appear as the most evident threats that menace the global STS and by consequence businesses, but also because the counter-measures for them subsume external action of business towards resilience against more "local" threats, as terrorist attacks, supply-chain disruption or, as above, insufficient demand.

In reflecting on counter-measures for such threats, it comes out that the decision-making of governments is key in achieving the required global coordination for avoidance of the threats. In the presented analysis, we point the following measures for each: redeploying military units to more civilian missions required by STS, targeting minimal standards of life quality for societies and investing in replacement of combustibles and carbon dioxide capture at a global scale. Therefore, addressing these threats as external factors will require that businesses will influence and cooperate with governments.

Systemic resilience of present STSs requires the existence of a dynamics in the international network of states towards making first priority the goals of peace and civilization sustainability. Now, the interesting question is why aren't we there yet? Why aren't public and private organizations coordinating to stabilize resource depletion globally, or enhancing social cohesion? As scientists, we have a special responsibility to search answers to this question, because science triggered the civilizational burst we live in.

To understand how resilience can be realized or compromised we need a theory for the deviation observed between the ideal and the observed behavior. A concept for such theory is considered in Section 4 . We immerge the three types of organizations in a broader network of groups along which 
human beings naturally coordinate behavior. It is the dynamics among these groups that determine actual events.

A realist look at the network of groups that constitute societies shows that we should not expect that all groups would cooperate to increase civilizational resilience. Some will do, some will not. For the moment, the cooperation level has been enough, not only to avoid civilizational collapse, but also to advance civilization. Yet, to achieve increased global STS resilience a wide and deeper understanding of social dynamics and social power based on human group behavior must be attained. In this paper it is only possible to point such need.

In Section 5, we sum up the exposition. Generalized cooperation among the organizations that make up modern civilization or the global STS appears needed to counter the systemic threats of nuclear war and civilizational collapse. It looks that we are lacking a theory on the subject, a theory that would allow us to gather relevant data and assess the possibility of relevant action in increasing cooperation towards economic prosperity, peace, minimum quality of life standards and sustainable energy sources. Would such aims be attained, businesses and people in any organizations could frame the future more confidently and a new perspective of business or organizational resilience could emerge.

To end up this introductory section I would like to call the attention of the reader to an initiative in management education that I comment briefly as a case study. See Box 1.

Case study: Is a new paradigm in business thinking emerging? The $50+20$ collaborative initiative.

The proposals in this paper may seem at first far apart from current business management thinking. Yet they are indeed quite aligned with the $50+20$ initiative (50plus20.org). In their own words:

“ $50+20$ is a collaborative initiative that seeks to learn of new ways and opportunities for management education to transform and reinvent itself. We are asking critical questions about the state of the world, the emerging societal issues, the dominant economic logic, the purpose of business, the crucial role of leadership, and the challenges facing management education."

The initiative puts together business leaders and academia, represented by several prestigious business schools and technical universities A central concern of $50+20$ is to contribute for a deep change in business education, substituting a shareholder centered vision by a stakeholder centered vision and putting business sustainability as the core goal of management among other issues.

In itself, $50+20$ represents a significant quantum leap in business thinking towards more prosperous and secure societies. As social evolution advances and problems of social and environmental nature become more critical, it is to expect that this kind of change in business management thinking widely disseminates and its "strangeness" will fade. It would be gratifying if this paper would become an instrumental contribution for this change.

Box 1. A case study on emergent new business management thinking: the $50+20$ initiative.

\section{Resilience of Socio-Technical Systems}

\subsection{Human Societies Are STS}

The concept of socio-technical system (STS) has gained increasing attention in the literature [4-9], both in philosophical-conceptual [4-6] as in engineering terms [7-9]. The concept taken here for an STS is a bit broader. One will take an STS as a system that has a necessary social component and a necessary technical component. The social component means that in the system there are agents able to interact among them. Moreover, this interaction, according to behavior coordinating patterns, is necessary for the persistence in time and the development of the system. The technical component means that the agents use recurrently technical artifacts in order to attain endeavors of them. A technical artifact is understood as some object external to the agents' bodies. Moreover, such use is also necessary for the persistence in time and the development of the system.

This definition makes human groups, societies or even the whole human species socio-technical systems where the abstract word "agents" means concretely "human beings". Consider a human group of hunter-gatherers. It makes an STS because it exhibits social behavioral patterns that if dissolved 
would lead to the dissolution of the group. Moreover, it makes an STS because the group uses a set of technical artifacts (clothes, weapons, tools). If these would completely disappear without possibility of replacement, the members of the group would be facing death in a short-term.

Our current situation is not different in qualitative terms from the pre-historic groups of hunter-gatherers. Survival and development of our present days societies hinges both on behavioral patterns of people as well as on the functioning, not only of technical artifacts, but also of whole technical systems. A failure in the electrical power grid that would leave millions of people without electricity for months would strongly disrupt either developed or developing countries, making a disaster of size commensurate with the number of "millions" and the number of "months". It is easy to see that an area without electric power distribution for weeks should revert to pre-electrical technology. The carrying capacity of the area-imagine a dense populated city-could be suddenly exceeded and millions of people would see themselves as the hunter-gatherers of the previous "thought experiment" in a very crowded space. Actually, this threat is in the radar of people concerned with electrical and electronic systems resilience in the event of space storms [10,11].

The "thought experiment" of supposing that instantly some swath of technical systems disappears irremediably allows one to get, at least, an idea of the technical depth of the STS with respect to the swath disappeared. Two questions arise: how many people would die? How backwards in technology and equipment would go the survivors?

The same technique can be used to get an idea of the social depth of the STS. If people would change instantly some swath of behaviors what would be the consequences?

The situation we experience today is the STSs we live in are immensely deeper with respect to hunter-gatherers. An exceptional space storm or solar eruption that could be catastrophic for us would do no special harm to them. Depth comes not only from the technical systems that produce life conditions for most people being prone to disruption. Our STS are weaponized STS. This means that lots of socio-technical subsystems, armies and armed groups, stand ready to destroy productive technical systems-and people. As a third factor, we can add that as the complexity of the system grows it is to expect that we lose prediction capability: more unforeseen failures could stay unforeseen and happen.

\subsubsection{Socio-Technical Subsystems and Their Frontiers}

It is a useful common practice to divide a system into subsystems. The distinction of subsystems inside a system can result in collections of subsystems that overlap or do not overlap. If we divide the hardware of a computer into subsystems, we end up with a collection of subsystems that does not overlap. Technically, one says that we made a partition of the system because no two subsystems have elements in common.

That may not be the case with STSs. An STS can be divided in subsystems and many of them will be overlapping. Let us assume that the whole human species and its accompanying technical paraphernalia constitute the global STS. Now consider a division of the global STS in subsystems, each subsystem being a state. States define a partition of the global STS in what respects terrestrial surfaces (taking out disputed lands), but only a quasi-partition in what respects people because some people are citizens of two or more states.

Now, let us consider organizations, as socio-technical subsystems of the global STS, for example, multi-national corporations, or inter-national organizations. It is clear that these subsystems overlap with the subsystems that we call states.

Other subsystems can be considered along other criteria. Spoken languages define subsystems of the global STS. Speakers of a given language define the social component of a subsystem and the technical means necessary for the use, preservation and evolution of the language define the technical component. We can note that languages define a quasi-partition of the global STS because some people speak several languages and therefore participate in more than one linguistic community. Again, we see that linguistic subsystems overlap with the subsystems states and organizations. 
The same could be said of religions, of cultures in general and of professional activities. Religions stress the spiritual side of humans, but it is clear that they rely on technical artifacts, as buildings and communication devices like books and imagery. So, in fact, a religion is a socio-technical subsystem of the global STS. Cultures also constitute subsystems of the global STS and the same can be said of professional activities. There is a social dimension in being a scientist, an engineer or a physician, as there is a technical dimension. Moreover, in these (and other) cases, there is a character of necessity in the referred subsystems. If we imagine that all the scientists with their labs would magically disappear, or all the engineer and their devices, or all the physicians and other personnel and medical equipment, then other people in the global STS would be in (dire) difficulties.

In summary, in the global STS (and possibly in many STSs), we can distinguish many subsystems according to several criteria. A criterion will generate partitions or quasi-partitions of the STS. Different criteria will generate overlapping subsystems. In this way, we can explore the inner structures of STSs and their connections.

\subsection{Resilience as Dealing with Failure}

The increasing depth—size and complexity—of the STSs we live in increases their vulnerability. It also requires a theory to deal with disturbance compensation or, more generally, system failure, well beyond the classical approaches of control or reliability and safety. The word "resilience" has been a catalyst in the search and realization of such a theory and in practical initiatives [12,13].

Several meanings can be assigned to resilience and are discussed in the literature [14-25]. The approach taken here is they represent legitimate concerns prompted by the increasing depth and vulnerability of STSs. The idea that emerges is that there are many interesting and useful concepts that could be bound together to a property of a system called "resilience". It also emerges that this property can be the object of engineering design or maintenance and that resilience engineering $[15,20,21,23]$ is now conceived as a proper engineering field.

In this paper, one assumes the following working definition: resilience is the property of an STS that avoids possible failures and minimizes bad outcomes for people when failures that were not avoided happen.

Recognizing as [15] that failures are unavoidable, resilience and resilience engineering is seen dealing with failure on a continued basis at whichever width of a system one may be interested.

This definition is agnostic with respect to the structural, parametric or functional changes that must happen to increase resilience. For example, [25] distinguishes between resilience as (the probability of) persistence in time and relative stability as the property of a system state to come back to an attractor after a disturbance. The authors in [24] distinguish between resilience and resistance, understood as some kind of "mechanical" opposition to a threat. The reasoning I follow here is as follows.

An STS must have a simultaneously centralized and distributed process to deal with failures. An STS that is better than another to deal with failures (of some kind) will be more resilient, or present greater resilience. Depending on the type of threat, the actions taken by the "dealing with failure" process can be of different types, as increasing relative stability margins, increasing shields, structurally transforming a subsystem to keep its functionality or any other. Therefore, no limit is previously assumed on how much the system may transform or which can be the actions taken.

Failures can be provoked or triggered by external or internal factors of an STS. Whatever the cause, the pattern of operation dealing with failure appears as invariant and presents three main functions.

With regard to controllability, failures can be classified as avoidable or unavoidable. This gives the basic strategy for resilience: avoid avoidable failures and have recovery or adaptation processes prepared for not avoided ones.

With regard to knowledge, a failure can be unknown, predictable or experienced. Unknown failures are failures from which we know only that we cannot rule out existence in a very basic footing. Unknown failures are those that we do not know what they could be, but that we assume cautiously that they may manifest. 
Depending on the consequences, when an unknown failure happens for the first time, the system may breakdown or not, but, truly, there is not much one can engineer in such a situation, except on an ad hoc basis. The system will react with whatever available resources and skills it can deploy and coordinate after the failure to counter its consequences. This reaction must proceed with knowledge that results from the failure having happened, because from a logical point of view, one cannot prepare a counter-measure to a threat that one knows nothing about. Therefore, we turn our attention to predictable failures, failures that one can assign a degree of making something meaningfully greater than zero, because we know something about them.

Note that there is a connection between avoidable and avoided failures and prediction. An avoidable failure can only be avoided if predicted. Therefore, a resilient system will invest a fraction of its energy and knowledge to search for predictable failures that did not happen yet. In addition, it will invest another fraction in developing counter-measures as avoidance, recovery or adaptation processes for predictable failures.

Predictable failures may have been experienced or not. In the first case, there are good chances that recovery processes for them are being bettered and, if the failure is avoidable, that avoidance processes are in operation.

Predictable but not experienced or under-documented failures may or may not enjoy due attention for avoidance, recovery or adaptation processes. This lack of attention may result in an economy of effort, if the failure does not happen, or in catastrophic losses, if the failure happens and so are the consequences.

The above reflections show that engineering resilience in STS includes three main functions: prediction of failures, development and implementation of counter-measures, to which one adds information and knowledge gathering from occurred failures.

On the Complexity of STSs

Socio-technical systems appear us as complex systems. The issue is relevant to system resilience, at least on the grounds of our intuition that a more complex system has more and unpredictable ways to fail than a less complex one. Yet, there is no agreed definition for system complexity [26]. People working in the field associate several properties to a complex system. Here, I will take the meaning given by Simon [27]: "Roughly, by a complex system I mean one made up of a large number of parts that interact in a nonsimple way".

In my perspective, two ideas associated to complexity are of special importance with regard to resilience. First, one must consider the distinction between complication and complexity, signaled by Rosen [28]. A complicated system has many parts, but they interact in a simple way. This has as consequence that if we map the parts and their interactions, we will be able, in principle, to model and predict the system behavior.

Second, one must consider that many complex systems are unpredictable in the "long" run. Some nonsimple interactions, technically nonlinear interactions, imply that we should have infinite information about the system's state to make "long term" predictions. Because we can only get a finite amount of information, even if we have a correct model, we are only able to make predictions for a "short" time span. Systems with this property are said sensitive to initial conditions and exhibit chaotic behavior or "chaos". A well-known example is the weather.

In real systems, we find a mix of complication and nonlinear interactions leading to unpredictability in variable proportions. Both affect resilience in different ways. Complication means many elements. Having a great number of agents can be beneficial with regard to predictability: while the behavior of an individual human being is quite unpredictable, the behavior of one million human beings can be quite predictable. On the other hand, the existence of many elements means that one must have the capacity to gather and interpret big amounts of data. Being unable to do so may have as a result that failures will happen because real systems are both complicated and complex. 
Nonlinear interactions leading to unpredictability pose another problem. A minute deviation of the actual system state from the perceived one can lead to a system's behavior very different from the anticipated one. This is metaphorically referred as the "butterfly effect".

Now, it is possible to recognize that the design of technical artifacts and systems is predicated on predictability. If a system does not behave as predicted (and desired), one speaks of failure. Most of the work of engineers amounts to suppress or limit nonlinear interactions introducing chaotic or unpredictable behavior in devices. Consider the device (computer or other) where you are reading this paper. It is a hugely complicated system with billions of components, yet its behavior is predictable. Actually, generations of engineers worked for such a result.

With regard to STSs, I observe again that they have a social or human component and a technical component. Technical artifacts, if properly designed and maintained, should not pose the bigger problem for resilience, but humans should do, for two reasons. One, humans are genuinely complex, and two, we do not know enough about human social behavior.

To deal with complexity, the concept of "edge of chaos", first spotted by Langton in computation [29], can be useful. Generalizing the concept, we got the idea that life, and therefore human societies, exist in a "tiny band" (the edge) between non-chaotic highly ordered systems and chaotic systems. If human societies are pushed too much to the ordered side they will go into sclerosis and eventually implode. If they are pushed too much to the chaotic side they will eventually disintegrate.

\subsection{People and Organizations}

In reflecting about designing systemic engineering resiliency, we cannot focus only on the functions referred above, prediction of failures, development of counter-measures, knowledge gathering from occurred failure. Functions are going to be implemented by organizations of people. We cannot forget who the real actors are and which are their sizes.

Socio-technical systems differ in the size of the system one wants to consider in the analysis. In this paper, the vastest STS considered is the human species. Then, following a geographically contiguous criterion, one could consider states and nations, regions and cities. Following a networked criterion over the above one can consider businesses, non-profit organizations and public organizations. Some organizations may be inter-national in that they can rule wider than states, according to some agreed mechanism of decision.

We consider primary public organizations those that have the power to impose the payment of taxes in a given territory in a designated currency. This makes states as the primary public organizations to consider, with secondary organizations being inter-national organizations funded by states. Given that states can be very large organizations, it is useful to consider a state as being decomposable in a network of public organizations.

Private organizations cannot impose the payment of taxes. We use the label "non-profit" for those that get funding through fees, donations or subsidies. We use the label "businesses" for those that that get funding through selling something that others want to buy.

\subsubsection{Monetary Coordination Structure of Global Civilization or the Global STS}

The above usual classification of organizations into public ones, non-profits, and businesses, is based on the relation of said organizations with money in a shallow view. Beneath these obvious distinctions, lies a most important process of coordinating human behavior in any STS: the monetary process of coordination. One can-and should-interpret money as a tool or artifact in a system that coordinates people and organizations inside a state [30], and to some extent, that coordinates states themselves. The use of money can be understood as exercising a technique for coordination in an STS. To see this, one may use a "negative" thought experiment. Nowadays, most of money exists not as "mechanical" paper notes or coins, but as electronic registers in computer systems that not only "store" money but also process monetary transactions. Imagine that these systems would blow up 
during night. What would people do in the morning? How could they get the continuous coordination necessary to produce and distribute things?

Let me try to give a quick sketch of how the coordination system using money as a tool works. First, one observes that in developed-or developing-economies, a crucial number of things that people need can only be accessed by buying them, so, people need to earn money. This can only be done by participating in a public or private organization. Public organizations, at least in a nominal sense, have the charter of realizing some social useful function. The same applies to private organizations (I am not taking in account illegal or criminal activities and organizations). In the case of businesses, the usefulness of their function is directly measured through sales exceeding costs. Nominally, this leads people to coordinate their behaviors in social useful ways.

It must be noted that states, or more exactly, governments, i.e., the legislative and executive branches of a state, have a key role in the overall coordination process because they perform the functions of decision making on top problems at the widest level for the state STS. The key role comes from the fact that a government has the powers to keep armies and police forces, establish laws or setting the basic operating rules for the society, enforce their observance and direct (at large for the private sector, more strictly for the public one) the social and economic activity in its area of jurisdiction. Among these powers, it is included the power of monopolistically issuing the currency each state designates for the payment of taxes. Issuance of currency can be negative or positive. It is negative when the government taxes because as a result people or private organizations are left with less money. It is positive when the government spends because as a result people in public organizations and in the private ones that sell products to the government are left with more money. The powers of selectively spending and taxing, together with legislating, mean that governments have decisive tools to steer the economies of their jurisdictions.

Now, for several reasons, the role of governments in the issuance of money and their responsibilities in the overall coordination process are badly understood. We may consider another thought experiment. Let us imagine that some government $y$, not being the government of state $x$, would announce that would begin issuing currency named as the currency of state $x$. We can see that this is not a possible move for government $y$. It would be considered a counterfeiter and possibly give origin to a casus belli. This shows that as long as a state is considered a state by other states it has the power of issuing its own currency and the correlated responsibility of managing issuance in the generalized sense (spending and taxing) in the public interest of their citizens.

The three powers of legislating, spending and taxing make the government a key agent inside an STS that we call a country. A government is as source of coordination for private and other public organizations. Inside the physical resources of its country it can induce an economy of prosperity. Business resiliency, in the bare sense of not becoming bankrupt or of bottom-line resilience, very much depends on governmental decisions to induce prosperity. Therefore, we may expect that systemic resilience at a global level very much depends on governments, their decisions and the level of coordination that they can achieve among them and with other organizations. This is investigated in the sequel, with regard to major global threats.

We must note that the above description of organizations and their relations implicitly assumes that all people in all organizations are reasonably benevolent towards other people. In this view, problems with resilience, as any other problems, would result mainly from ignorance or unawareness. This is not true: not all people are benevolent for all people all the time and some are malevolent all the time. In coordination and cooperation studies, the first ones are usually called cooperators and the last ones are called defeaters. This last group is the most dangerous for an STS because malevolency will result in a continuous tension to trigger failures in the STS. This is an unsolved problem for resilience engineering of STS. One should remember that we are dealing with socio-technical systems, systems with a necessary social component; therefore, social behavior becomes necessarily a factor to consider in engineering. 
The approach taken here is to assume that most people in organizations are reasonably benevolent; therefore, they are cooperators and see what becomes required in the cases under study. In this approach, defeaters are treated as an uncompensated perturbation at any level of an STS. In Section 4, a sketch for a theory of social dynamics is being presented that will allow a more direct consideration of defeaters.

\subsubsection{Prosperity in the Global STS as a Standard of Quality for Societies}

In the introduction, I made the case that prosperity of societies is a necessary condition for bottom-line business resilience in general. It is appropriate to hint, or better, stress, that in the conceptualization of societies as STSs prosperity does not appear as some unattainable condition or as a condition subject to unknowable and uncontrollable destructive forces-as one could be led to believe just by hearing or reading what is mostly said and written.

Let us consider some facts. Taking the Industrial Revolution as a, somehow arbitrary, departing point in a time interval going to nowadays, it is clear that the application of science and technology to the production of artifacts, devices and systems had as a consequence a huge positive leap in the human experience manifested in the expectation of life duration and quality of life for most people. Such an increase had a cost in resources, but this cost is manageable. So, science and technology are and will be here to create and sustain the material basis of prosperity. Disregarding some doubts on getting clean energy in the amounts needed, it is therefore clear that lack of prosperity, at the global level, is not caused by technological shortcomings.

The question can be more concretely posed at the level of a state STS. As an STS it has two components, social and technical. The citizens of the state STS, their productive knowledge and organizational capabilities, together with the technical equipment and natural resources controlled by the STS define an envelope of real possibilities on which a plan to attain prosperity must be based. As of now, it appears that no state STS is self-sufficient, so a plan to attain prosperity must also rely on international cooperation, beginning with trade. Should such plans be adopted by a critical number of countries, a global phase shift to prosperity is possible, because at the planetary level the required initial knowledge and equipment exists together with all the natural resources.

The hallmark of such plans is being inclusive and realistic. Actually, they are not difficult to devise. They result from applying scientific reasoning to known data, the application being grounded on an ethical choice and a pragmatic view. The ethical choice requires that one includes all humans in the category of human beings where one puts oneself. The pragmatic view acknowledges that humans have limitations and operate under several constraints that block the transition to global prosperity.

It appears to me that a promising way to resolve the tension between the possibility of global prosperity and its antagonist factors is indicated by the idea of interpreting prosperity in an STS as said STS realizing a standard of quality for the human society it embodies. The standard of quality defines the target prosperity with regard to the envelope of real possibilities. The word realization reminds us that such standard of quality will not happen by decree but by tenacious work, civic compromise, interplay and cooperation of public and private organizations.

\section{Business Resilience and its External Global Dimension}

\subsection{The Resilience of Businesses}

\subsubsection{What is a Business?}

We are now in a position to think business resilience in the socio-technical terms developed above. In a modern STS, coordination of productive activity occurs through a process that has money as the key device. Nominally or ideally speaking, people must earn money to get what they want or desire and they can do this only by coordinating activity with others so that the production of useful things for people results. 
Businesses constitute a type of organizations that work under the following constraint: proceeds of sales must equal payments made along a time average. Coupling this constraint with a "competitive market" makes businesses align their products to the preferences of buyers. To the extent that a market is competitive and fairly regulated this arrangement has shown effective to structure the socio-technical production of "marketable" goods and services—for a negative example, one can take the the Soviet Union and its spectacular collapse.

Yet, buyers are not the only stakeholders of businesses. Participants in businesses also are stakeholders. Participation in a business can follow two schemes: partnership-only or partnership plus the employer-employee relation. Theoretically, the partnership-only scheme is more efficient to satisfy interests of both buyers and participants. In practice, it represents only a small fraction of businesses. The partnership (of employers) plus the employer-employee relation represent the vast majority of businesses. This scheme has an inherent conflict of interests: it is in the interest of employers to maximize the productive effort obtained by paid compensation, while the opposite is true for employees.

The inherent problem in the employer-employee scheme has been overcome, better or worse, by the simple fact that most people (either employers or employees) are benevolent and adapt behavior, besides governments enacting legislation that alleviates the negative social impacts of the scheme. At first sight, the differences between the two schemes do not preclude a common theory of business resilience.

\subsubsection{The Resilience Process in Business}

A business is an STS that is a subsystem of a larger system (or several larger systems). It is potentially subject to failures. Failures can have an internal cause, an external cause or a mix of the two. The resilience process of a business must perform the three functions referred above: predict possible failures, develop counter-measures to possible failures and gather information. Because failures can have internal and external factors, they must be addressed in two directions: one internal, the other external. We can think the resilience process of a business as having two (sub)processes. The internal process will target actions for avoidance and response to threats that only depend on the capacities of the business. In contrast, the external process will target actions to influence the environment where the business operates.

So, let us say that a business aims to become more resilient with regard to terrorist attacks. The internal resilience process will address the operational procedures that can make the business minimize the losses and recover faster after such an event. The external resilience process will target to influence the government to deploy a more effective protection (short term) or influence governments in general to enter a pacification process (medium to long term).

Or, let us consider the "eternal" threat of the business' bottom line going into the red. The internal resilience process will address costs and efficiency of operations. The external resilience process may select to do an advertising campaign (short term) or influence governments to increase society's prosperity (long term).

There are many possibilities to conceive the operation of the external resilience process and many possible choices of which threats to address. In the following section, I consider two threats that are top-level in the sense of threatening the continuity of the global STS. They are threats for businesses-and for people in general-therefore they should be targets for action in the external resilience process of any business. 


\subsection{Two Major Threats to the Global STS}

\subsubsection{The Case of Nuclear War}

Political events of the last years raised the perceived risk of a nuclear war. According to recent research [31,32], the prediction is still the same of the "old" research: the ensuing nuclear winter would wipe off civilization, if not the whole human species.

It is clear that such an event would be the "supreme" failure that the STS we live in could undergo: a kind of suicidal act. Let us note that the threat for this failure comes potentially not only from conflict among nuclear powers, but also from technical failures on monitoring radars [33].

Conceivably, what could increase the probability of avoiding such a complete failure? It seems more or less clear that the majority of businesses and people working in them, producing goods and services, are interested in a generalized climate of peace, one that would minimize the risk of war, including nuclear war, and maximize opportunities of useful and profitable deals. Taking in account that not all businesses are of such interest and not all people are benevolent in general, the question is how those that do can influence public organizations, deciding on peace and war, to choose peace-enabling policies?

The solution for this problem can be deemed conceptually simple: the major military powers decision makers must recognize the futility of being able to wage war unless in self-defense. It makes little sense to be able to grab territory and resources in a civilization that disappears. The logic of nuclear dissuasion is that nuclear weapons should never be used. This logic very much applies to other military equipment. If this is so, it must benefit people in general a lot to reduce the cost of keeping and developing equipment that should never be used.

In this perspective, the actual military and industrial units should be redeployed for self-defense, systemic resilience or even businesses like sport spectacles and games. Note that for all countries, as for all people, the capability of self-defense should not be abandoned because the probability of threats that require it cannot be set to zero.

A proposal for a realignment of attitudes with peace as first factor and the reconversion of the risky and useless war units into self-defense, resilience and peaceful business units should not be presented alone. If there is a risk of civilization collapse by other reasons other than war, self-defense becoming war may very well happen after all. If civilization goes towards collapse by the reasons indicated in the next section, armed conflicts will ensue because resources will become critically scarce or social cohesion will go below critical levels.

\subsubsection{The Case of Civilization Collapse}

Historical collapses of civilizations have been recently analyzed and modeled. According to [34]:

"Virtually every past civilization has eventually undergone collapse, a loss of socio-political-economic complexity usually accompanied by a dramatic decline in population size."

These collapses have been regional. The question that one poses now is if our global civilization (or global STS in this paper terminology) or some swath of it will also collapse?

In [35] a classical analysis of the possible causes of civilization collapse is made. Here, I follow a theoretical model proposed in [3]. The authors consider two factors for collapse: depletion of natural resources and wealth stratification of population into "commoners" and "elites". The model is able to reproduce qualitatively dynamics of historical collapses. The annoying —or alerting — aspect of this model is the so-called "developed countries" show both signals. Beyond consumption of resources above the carrying capacity, in the last decades they present increased widening of income and wealth distribution, with a decreasing share for "commoners", labor conditions worsened and increasing unemployment.

One may signal that some businesses with particularly humanist and creative leaders have attained interesting results with regard to inclusive policies that counter wealth stratification. Yet, 
the fact stays that unless the business is a monopoly, it operates in a competitive market. As referred above, market competition has some advantages for buyers, like increased attention of businesses to their wishes, but it also has some hidden and strong disadvantages unless public government sets appropriate rules of the game. A general "rule of the game" for businesses is that they will not pay for something unless they are obliged to. Without adequate public governance, this will mean that, in general, an environmental and social responsible entrepreneur will go with the competition or will go out of business.

As well for employment it is very little appreciated that under the rules of market competition businesses are not geared to employ people; they are geared toward dis-employing people. Against, this has nothing to do with the benevolence of management but with the bare fact that a business cannot stay much time in the red whichever is the cause.

This "race to the bottom" extends to economic relations among countries. Again, the institutionalized decision that can make a difference is in the hands of public organizations responsible for public government, because governments are the agents that can contract inter-national economic relations among countries that are win-win, in the sense of being profitable for the vast majorities of their populations.

In a sense, the wealth stratification factor appears easier to tackle than resource depletion because theoretically it appears mainly as a social factor. It has become common practice to require that technical artifacts and systems comply with quality standards. The idea can be extended to STSs. Given that we are considering human societies as STSs, I propose that a minimal standard of quality for societies should be deployed similarly to the existing standards for technical-only components.

While this may seem farfetched and quite difficult at first sight, I further suggest that a document embodying such a standard already exists as the Declaration of Human Rights (DHR) from the United Nations (UN) [36]. Realizing a minimal standard of life for all citizens should eliminate or limit the effects of wealth stratification. This can be done by a coordinated global action of governments and other public organizations, non-profits and businesses. The major countries-or socio-technical subsystems-should have here (as in the case of peace) a role of persuasion by example. I remember that prosperity leads to increased demand and adequate demand for a business's products is key to their resilience.

The seemingly more difficult part with this approach comes from the implied resource depletion side. Life, at any standard of quality, requires energy and most of energy we need [37] comes from combustibles. This sources carbon dioxide into the atmosphere that is not sunk and global warming ensues with high probability of very dangerous effects [38]. The effects of global warming include a reduction of livable territories areas [39] with mass migrations upsetting the equilibrium obtained among nations in what respects occupied territory. Therefore, by sourcing energy mostly from combustibles we are depleting down to very dangerous levels a critical resource of our and any civilization: space for people to live and produce the things required for their life.

For the warming to stop, we must stop sourcing carbon dioxide or we must sink it out, otherwise the "allowable thermal point of operation" of the STS we live in will be exceeded. For our civilization to continue we should do both: develop technologies for substituting combustibles as energy sources and for sinking or "sequestrating" carbon dioxide. Rather than cooperating for these first priority goals, states are conflicting about questions that literally will evaporate if global warming continues unchecked.

Although, by law, businesses have no direct intervention in government, they surely can have a catalyzing role of public opinion and the possibility to strongly argue the need for and influence governments to take policies addressing these general issues of continuity for the global STS. On this matter, I would call again the attention of the reader to a report that I present as a case study in Box 2. 
A case study of case studies: A sample of how companies see governmental action in building resilience.

Will businesses come to require and influence governments to tackle the global issues in business resilience raised in this paper?

The National Round Table on The Environment and Economy of Canada produced several reports. One of them (available here: http://neia.org/wp-content/uploads/2013/04/cp5-case-studies.pdf [40]), "Facing the Elements: Building Business Resilience in a Changing Climate (Case Studies)", documents the approaches for increasing resilience to climate change taken by thirteen companies operating in Canada. The documentation covered the same items for all companies and one of them was the perspective on government roles held by companies.

Going through all the thirteen perspectives, it becomes clear that companies expect governments to take due diligence and action in public matters, including legislation, research, advance information and education. They also show willingness to cooperate with governments and display understanding that some problems cannot be solved without cooperation.

It turns out that companies are committed to increase their resilience and distinguish clearly what should be done by governments, by themselves and in cooperation.

I conclude that the question is fundamentally one of awareness. Twenty years ago, a report as this one would be near to unthinkable. It is to expect that a raising awareness of business resilience depending on actions targeting global problems will raise the requirements of businesses with regard to governments' decisions.

Box 2. A case study of case studies: how thirteen companies operating in Canada described their views of what governmental action should be in building resilience to climate change.

\section{The Network of Human Groups under Organizations}

Differently from all other we know, we are technical animals. We use tools. With tools we keep us alive. With tools we enslave or kill other humans. The more one tests the concept, the more one sees that one cannot dissociate being technical from being human. In a sense, many animals are technical in that they exhibit complex and intelligent behaviors producing the results they need. But we only use consistently objects as tools, so maybe it is more correct to say that we are instrumentally technical animals.

This "technicality" could not have evolved without us being social animals. We discovered a very advantageous general process: pass to the next generation the techniques and equipment created. This process could have been very slow at beginning, but accelerated whenever civilizations emerged. From the birth of science in Europe, in a crescent pace of growth, the process attained the actual levels of knowledge and technology. Human societies are socio-technical systems.

How wondering can be some realizations of present day science, technology and our STSs, we must not forget that a dark side of it exists. Europeans disseminated the foundations of modern science and technology in the globe, together with colonization, genocide, enslavement, war and exploitation. While globally the social and inter-national situation has been ameliorating, the fact remains that if we take the full realization of UN DHR as a standard of quality for STSs, only a few countries (if any!) will pass the test. We can connect this to the fact that our STSs continue exposed to the threats of nuclear war or civilization collapse, as pointed in the last section. So, despite the realized technological feats, we must acknowledge that our STSs are still of a quite rude or primitive level as they still did not manage to implement credible counter-measures for the pointed threats.

Let us take the question of existence of more advanced STSs in abstract—as we do not know any other except our own. It is conceivable that such more advanced STSs should have realized minimal quality standards of life and made them sustainable by avoiding the threats above. If besides being conceivable, such STSs are possible, there must exist a path from an STS as ours to an advanced STS.

Some components of such path may be technical as developing usable sources of energy without the problems entailed by combustibles. However, the simple fact that efforts in such direction are not first priority in the inter-national coordination of states shows us that the social components must be investigated.

Our classification of organizations as public and private, non-profit or business is a standard one in the reference frame adopted. This frame supposes monetized national economies with property rights, 
supported and generally directed by states that enforce law and provide public services. Another assumption we took was that most people in organizations are reasonably benevolent.

These assumptions appear unsatisfactory to explain the observed behavior of our STSs. If there is a possibility that a successful large-scale cooperation towards resilience of the global STS may emerge, better models for analysis must exist and we should discover them. Here we will propose the following hypothesis.

Human social dynamics is determined, at the social realm, by the cooperation and conflict of the several (or many!) overlapping groups that form naturally in the human species.

As examples of such groups one can point out that humans group themselves naturally: by gender and by age; by geographical distance, genetics and cultures forming nations; by choice of fundamental descriptions of reality forming religions; by "chunks" of Earth surface, forming states, and by ethical choices and cognitive levels forming groups with a kind of collective intelligence that serves the choices and operates within the cognitive level.

The last type of groups is of special interest. Above, I suggested that "economic prosperity" plans must be based on an inclusive ethical stance that puts all human beings in the same category as oneself. Yet, on a realistic perspective, taking such stance will not be often the case. Rather, one can observe a spectrum that goes from the benign case where one cares about the others as a function of perceived proximity (of family, of community, of country) to the case where individuals or groups of individuals consider most of other people as objects proper to be exploited, killed, enslaved or any other malevolency that may satisfy personal or group greed or result from ignorance, prejudice or herd behavior.

It follows that human social behavior exists in a spectrum that, from the perspective of an STS, can go from an extreme of cooperation to an extreme of "anti-cooperation". For "anti-cooperation" I mean a behavior that is coordinated and has as result the worsening of living conditions and resilience. It is clear that an advanced STS requires a level of cooperation geared towards resilience, and therefore a level of "anti-cooperation" inhibition, substantially greater than it exists in most of our STSs.

A practical implication of the hypothesis is the following. To assess the possibilities of cooperation among organizations one should begin by determining who are the relevant decision-makers in the organizations and in which "deep" groups they position themselves, in particular with respect to the cooperation versus "anti-cooperation" spectrum.

\section{Conclusions}

In this paper, I have followed a dimension of systemic analysis of interest for business resilience proposed by the author of [1]: shouldn't businesses care first for global systemic resilience rather than business resilience?

As I have argued in the introduction, the question does not pose itself in terms of "rather than". Global systemic resilience is of direct and immediate interest to business resilience. Properly seen, it appears unavoidable that businesses must address resilience through a process targeting internal factors and a twin process for targeting external factors. In the sequel, I have developed this concept of resilience having an "environment targeting arm" and I argued that addressing top-level threats for the global STS should continuously be in the action program of this "arm".

To this aim, I conceptualized human societies and the human species as STSs. Resilience was understood as an engineering function of an STS directed to deal with failures, under conditions of system complexity. This function includes prediction and avoidance of large-scale failures. Following this, I presented a model for the relations of organizations in an STS based on the concept of money being the tool for a global coordination of activity.

Upon the above concepts, I indicated a characterization of businesses as subsystems of larger STSs in connection with the coordination mechanism above. Taking seriously the idea that business resilience should be taken by two "arms", I have proposed that the "external arm" should include the addressing of two main threats to the global STS: nuclear war and civilization collapse induced by 
simultaneous wealth stratification and resource depletion. Possible counter-measures were advanced, respectively, reconceptualization of the systemic role of military units, realizing a minimal standard of quality in societies, viz., the UN DHR, and investing heavily in developing usable substitutes of combustibles as energy sources.

While the logical thing to do for businesses is to influence and cooperate with public opinion and governments towards a process of contention of such threats, I advanced the hypothesis that sectorial interest groups can capture governments-and organizations in general-or constrain them to act on their behalf, actually blocking, delaying or making such processes difficult. Global systemic resilience can be advanced commensurately with the extent that governments can take systemically cooperative behaviors and social groups allow or press them. This, as already noted, will require the cooperation and interplay of all concerned citizens and organizations in the global STS for which businesses can behave as a catalyzing force through their resilience programs.

Acknowledgments: I would like to thank the two anonymous reviewers for criticisms that allowed me to sharpen the generalized concept of socio-technical system and to fuse a general concept of global resilience with business resilience. This paper was financially supported by COMPETE: POCI-01-0145-FEDER-007043 and FCT-Fundação para a Ciência e Tecnologia within the Project Scope: UID/CEC/00319/2013.

Conflicts of Interest: The author declares no conflict of interest.

\section{Abbreviations}

The following abbreviations are used in this manuscript:

STS

socio-technical system

STSs socio-technical systems

\section{References}

1. Muff, K. Planetary Resilience. PwC-Resilience Journal. Available online: http://www.pwc.com/gx/en/ services/advisory/consulting/risk/resilience/publications/planetary-resilience.html (accessed on 28 November 2015).

2. Brown, J.R.; Fehige, Y. Thought Experiments. In Stanford Encyclopedia of Philosophy; CSLI Stanford University: Stanford, CA, USA, 2014; Available online: http://plato.stanford.edu/entries/thought-experiment/ (accessed on 23 January 2016).

3. Motesharrei, S.; Rivas, J.; Kalnay, E. Human and Nature Dynamics (HANDY): Modeling inequality and use of resources in the collapse or sustainability of societies. Ecol. Econ. 2014, 101, 90-102. [CrossRef]

4. Ropohl, G. Phylosophy of socio-technical systems. Soc. Philos. Technol. 1999, 4, 186-194.

5. Ottens, M.; Franssen, M.; Kroes, P.; van de Poel, I. Systems Engineering of Socio-Technical Systems. Available online: http://www.tbm.tudelft.nl/fileadmin/Faculteit/TBM/Over_de_Faculteit/Afdelingen/ Afdeling_Values_and_Technology/sectie_filosofie/medewerkers/Maarten_Ottens/Publications/doc/ Systems_engineering_of_socio-technical_systems.pdf (accessed on 28 November 2015).

6. Kroes, P.; Franssen, M.; Poel, I.V.D.; Ottens, M. Treating socio-technical systems as engineering systems: Some conceptual problems. Syst. Res. Behav. Sci. 2006, 23, 803-814. [CrossRef]

7. Baxter, G. Socio-Technical Systems. In LSCITS Socio-Technical Systems Engineering Handbook; University of St Andrews: St Andrews, UK, 2011; Available online: http:/ /archive.cs.st-andrews.ac.uk/STSE-Handbook/ (accessed on 28 November 2015).

8. Baxter, G.; Sommerville, I. Socio-technical systems: From design methods to systems engineering. Interact. Comput. 2011, 23, 4-17. [CrossRef]

9. Fischer, G.; Herrmann, T. Socio-technical systems: A meta-design perspective. Int. J. Sociotechnol. Knowwl. Dev. 2011, 3, 1-33. [CrossRef]

10. Radasky, W.A. Overview of the impact of intense geomagnetic storms on the US high voltage power grid. In Proceedings of the IEEE 2011 International Symposium on Electromagnetic Compatibility, Long Beach, CA, USA, 14-19 August 2011; pp. 300-305. 
11. Fry, E.K. The Risks and Impacts of Space Weather: Policy Recommendations and Initiatives. Space Policy 2012, 28, 180-184. [CrossRef]

12. International Strategy for Disaster Reduction. Hyogo Framework for Action 2005-2015: Building the Resilience of Nations and Communities to Disasters. In Proceedings of the World Conference on Disaster Reduction, Hyogo, Japan, 18-22 January 2005.

13. Centre for Integrated Emergency Management. Smart Mature Resilience. Available online: http://ciem. uia.no/project/smart-mature-resilience (accessed on 28 November 2015).

14. Handmer, J.W.; Dovers, S.R. A typology of resilience: Rethinking institutions for sustainable development. Organ. Environ. 1996, 9, 482-511. [CrossRef]

15. Hollnagel, E.; Woods, D.D.; Leveson, N. Resilience Engineering: Concepts and Precepts; Ashgate: Aldershot, UK, 2006.

16. Robert, B.; Pinel, W.; Pairet, J.Y.; Rey, B.; Coeugnard, C. Organizational Resilience-Concepts and Evaluation Method. Available online: http://www.polymtl.ca/crp/doc/Organizational-Resilience.pdf (accessed on 28 November 2015).

17. Vogus, T.J.; Sutcliffe, K.M. Organizational resilience: Towards a theory and research agenda. In Proceedings of the IEEE International Conference on Systems, Man and Cybernetics, Montreal, QC, Canada, 7-10 October 2007; pp. 3418-3422.

18. McManus, S.; Seville, E.; Vargo, J.; Brunsdon, D. Facilitated process for improving organizational Resilience. Nat. Hazards Rev. 2008, 9, 81-90. [CrossRef]

19. Haimes, Y. On the definition of resilience in systems. Risk Anal. 2009, 29, 498-501. [CrossRef] [PubMed]

20. Madni, A.M.; Jackson, S. Towards a conceptual framework for resilience engineering. IEEE Syst. J. 2009, 3, 181-191. [CrossRef]

21. Rahimi, M.; Madni, A.M. Toward a resilience framework for sustainable engineered systems. Procedia Comput. Sci. 2014, 28, 809-817. [CrossRef]

22. Lundberg, J.; Johansson, B. Systemic resilience model. Reliab. Eng. Syst. Saf. 2015, 141, 22-32. [CrossRef]

23. Woods, D. Four concepts for resilience and the implications for the future of resilience engineering. Reliab. Eng. Syst. Saf. 2015, 141, 5-9. [CrossRef]

24. Longstaff, P.H.; Armstrong, N.J.; Perrin, K.; Parker, W.M.; Hidek, M.A. Building Resilient Communities: A Preliminary Framework for Assessment. Homel. Secur. Aff. 2010, 6. Article 6. Available online: https:// www.hsaj.org/articles/81 (accessed on 23 February 2016).

25. Holling, C.S. Resilience and Stability of Ecological Systems. Annu. Rev. Ecol. Syst. 1973, 4, 1-22. [CrossRef]

26. Ladyman, J.; Lambert, J.; Wiesner, K. What is a complex System? Eur. J. Philos. Sci. 2013, 3, 33-67. [CrossRef]

27. Simon, H. The architecture of complexity. Proc. Am. Philos. Soc. 1962, 106, 467-482.

28. Rosen, R. Life Itself. A Comprehensive Inquiry into the Nature, Origin, and Fabrication of Life; Columbia UP: New York, NY, USA, 1991.

29. Langton, C. Computation at the edge of chaos: Phase transitions and emergent computation. Phys. D 1990, 42, 12-37. [CrossRef]

30. Garrido, P. Coordination of systems through numeraires. FME Trans. 2015, 43, 377-385.

31. Robock, A.; Oman, L.; Stenchikov, G.L. Nuclear winter revisited with a modern climate model and current nuclear arsenals: Still catastrophic consequences. J. Geophys. Res. 2007, 112, D13107. [CrossRef]

32. Federation of American Scientists; Starr, S. Nuclear War, Nuclear Winter, and Human Extinction. Available online: https://fas.org/pir-pubs/nuclear-war-nuclear-winter-and-human-extinction/ (accessed on 28 November 2015).

33. Wikipedia. 1983 Soviet Nuclear False Alarm Incident. Available online: https://en.wikipedia.org/w/index. php?title=1983_Soviet_nuclear_false_alarm_incident\&oldid=691300611 (accessed on 18 November 2015).

34. Ehrlich, P.R.; Ehrlich, A.H. Can a Collapse of Global Civilization Be Avoided? Proc. R. Soc. B 2013, 280. [CrossRef] [PubMed]

35. Tainter, J. The Collapse of Complex. Societies; Cambridge University Press: London, UK, 1988.

36. United Nations. The Universal Declaration of Human Rights. Available online: http://www.un.org/ Overview/rights.html (accessed on 29 November 2015).

37. Wikipedia. Fossil Fuel. Available online: https://en.wikipedia.org/wiki/Fossil_fuel (accessed on 7 December 2015). 
38. Anderson, K.; Bows, A. Beyond "Dangerous" Climate Change: Emission Scenarios for a New World. Proc. R. Soc. A 2011, 369, 20-44. [CrossRef] [PubMed]

39. University of Cambridge. Center for Science and Policy. Climate Change: A Risk Assessment. Available online: http:/ /www.csap.cam.ac.uk/projects/climate-change-risk-assessment/ (accessed on 7 December 2015).

40. Facing the Elements: Building Business Resilience in a Changing Climate (Case Studies). Available online: http://neia.org/wp-content/uploads/2013/04/cp5-case-studies.pdf (accessed on 24 February 2016).

(C) 2016 by the author; licensee MDPI, Basel, Switzerland. This article is an open access article distributed under the terms and conditions of the Creative Commons by Attribution (CC-BY) license (http://creativecommons.org/licenses/by/4.0/). 